\title{
Urgences
}

\section{Lettre à quelqu'un}

\section{Raymond Vennes}

Numéro 9, 1er trimestre 1984

URI : https://id.erudit.org/iderudit/025136ar

DOI : https://doi.org/10.7202/025136ar

Aller au sommaire du numéro

Éditeur(s)

Urgences

ISSN

0226-9554 (imprimé)

1927-3924 (numérique)

Découvrir la revue

Citer ce document

Vennes, R. (1984). Lettre à quelqu'un. Urgences, (9), 49-52.

https://doi.org/10.7202/025136ar

Ce document est protégé par la loi sur le droit d'auteur. L’utilisation des services d'Érudit (y compris la reproduction) est assujettie à sa politique d'utilisation que vous pouvez consulter en ligne.

https://apropos.erudit.org/fr/usagers/politique-dutilisation/
Cet article est diffusé et préservé par Érudit.

Érudit est un consortium interuniversitaire sans but lucratif composé de l'Université de Montréal, l'Université Laval et l'Université du Québec à Montréal. Il a pour mission la promotion et la valorisation de la recherche. https://www.erudit.org/fr/ 


\section{RAYMOND VENNES}




\section{Lettre à quelqu'un.}

Mon bel amour de février, Ma chaleur au creux de l'hiver, Mon temps présent et à venir,

Je t'aime

Et répands autour de moi

Le pollen de ton amour,

Comme un printemps sans bon sens

Que l'on s'étonne de trouver dans mes yeux,

Au moment où tout un pays

Commence à prévoir les neiges et les gels.

Cette année, et l'an prochain et pour les siècles à venir, II n'y aura pas d'hiver, pas de neiges, pas de gels,

Pas d'autres saisons possibles

Que celle qui fait croître ma Paix et ma Joie,

Celle qui porte ton nom

Et qui fait de chaque temps,

Une éternité de soleil, de musique et de rires.

Hier

J'ai enterré la nuit qui me tuait à la dérobée.

Hier,

J'ai creusé de mes mains nues,

Une fosse immense où j'ai jeté pêle-mêle

Et sans remords

La Nuit qui me tuait d'angoisses, de désespérances,

De vide, de solitude et d'ennui.

J'ai enfoui au plus creux de la terre,

Toutes les amitiés fausses,

Tous les intérêts mesquins,

Les cris et les blessures qui témoignaient

D'un temps qui n'est plus et ne sera jamais plus.

Et quand j'eus soigneusement replacé la terre

Sur toutes les saletés accumulées,

Je me suis relelevé,

Droit comme une jeunesse en fleur

Au milieu d'un pays propre, 
Éclairé et sans douleurs.

Je me suis retrouvé nu

Comme à ma naissance.

Étonné d'un air si pur,

D'un silence si plein,

D'un soleil si chaud.

Étonné de m'entendre rire et pleurer,

Pleurer et rire,

Comme un enfant Fou,

Comme un enfant

Ivre de promesses et d'espérances.

II était onze heures au temps de tes yeux.

C'était le 26 février à l'été de ton corps.

Le début de tout à l'éternité de nos mains jointes.

Nous sommes maintenant UN homme

Nous sommes un homme en pleine force,

Et nos racines sont bien agrippées

Au pays qu'il nous reste à bâtir,

Aux couleurs de nous-mêmes.

Un pays sans fin

Où tu noueras les choses

Les unes aux autres

Comme un gigantesque macramé

Où j'accrocherai les mots

Comme des contes pour enfants

Qui nous garderont beaux et frais et ardents.

Un pays où nous mettrons ensemble

Les couleurs du Jour et de la Nuit,

Du feu et de l'eau,

De l'amour de l'un pour l'autre

Et de l'autre pour l'un,

Avec la ferveur des anciens

Quand ils disaient:

Pour les siècles des siècles, Je T'aime!

Février '76.

Un an déjà. 


\section{LE MONDE À VENIR.}

LE MONDE À VENIR

IL EST AU BOUT DE MES DOIGTS

QUAND JE RETROUVE

L'ENFANCE

ET QUE MA MAIN COURRE

SUR LA PEAU NUE DE TES SEINS

POUR RETROUVER

LE CHEMIN DE LEUR VÉRITÉ.

PUIS IL NEIGE...

IL NEIGE SUR LES SAISONS

DE MA VIE.

IL NEIGE SUR LE PAYS

QUE J'HABITE.

IL NEIGE

POUR QUE TOUT RESSEMBLE

À TA SPLENDEUR. 